International Journal of Medical Anesthesiology 2020; 3(3): 24-27

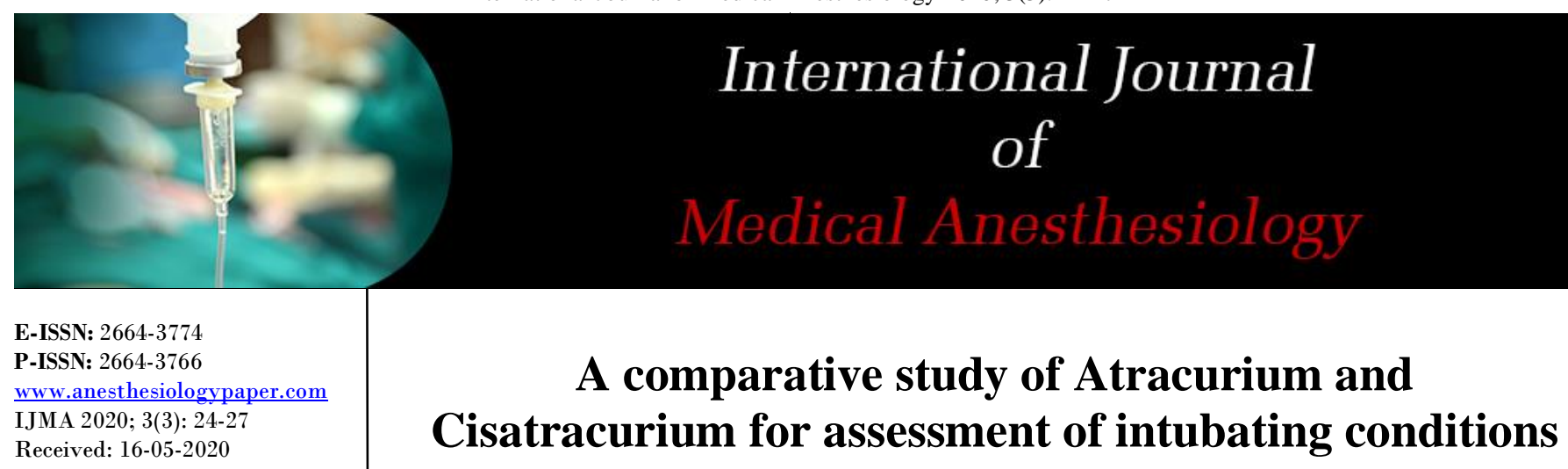

\author{
Dr. Jyoti Kale, Dr. Harshavardhan Arvind Mahadik and Dr. Priyanka \\ Madhukar Korde
}

Dr. Jyoti Kale

Department of

Anaesthesiology \& Critical

Care, $3^{\text {rd }}$ floor, New Building,

Smt Kashibai Navale Medical

College \& General Hospital,

Narhe. Pune, Maharashtra,

India

Dr. Harshavardhan Arvind

Mahadik

Snehalata building, $1^{\text {st }}$ floor,

Opposite KK Market, Punyai

Nagar, Dhankawadi, Pune,

Maharashtra, India

Dr. Priyanka Madhukar Korde Department of

Anaesthesiology \& Critical

Care, $3^{\text {rd }}$ floor, New Building,

Smt Kashibai Navale Medical

College \& General Hospital,

Narhe. Pune, Maharashtra,

India

Corresponding Author:

Dr. Harshavardhan Arvind

Mahadik

Snehalata building, $1^{\text {st }}$ floor,

Opposite KK Market, Punyai

Nagar, Dhankawadi, Pune,

Maharashtra, India

\section{DOI: https://doi.org/10.33545/26643766.2020.v3.i3a.142}

\begin{abstract}
Introduction: Muscle relaxation is used to facilitate endotracheal intubation, to provide surgical relaxation. While selecting neuromuscular agent for tracheal intubation main aim is to select agent with better intubating conditions, longer duration of action, better hemodynamic stability and good spontaneous reversal.

Materials and methods: This study is designed as randomized controlled clinical trial to compare between atracurium and Cisatracurium regarding onset, duration of action and intubating conditions. Group A received $2 \times E D 95$ dose $(0.5 \mathrm{mg} / \mathrm{kg})$ of Atracurium, group C received $4 \times E D 95$ dose $(0.2 \mathrm{mg} / \mathrm{kg})$ of Cisatracurium. Endotracheal intubation was done by using Train-Of-Four monitor, at TOF score 0 . Results: In our study, difference in mean Intubating condition score was not statistically significant. Mean onset time for group A was 3.7 minutes which was faster as compared to group $\mathrm{C}$ which was 6.04 minutes and mean duration of action for group $\mathrm{C}$ was 59.43 minutes which was significantly more compared to group A 38.93 minutes.

Conclusion: From above observations we conclude that, both the drugs provide comparable intubating condition. Atracurium $2 \times E D 95$ dose has faster onset \& shorter duration of muscle relaxation than Cisatracurium $4 \times$ ED95 dose.
\end{abstract}

Keywords: Atracurium, cisatracurium, different ed 95 doses, tof monitoring

\section{Introduction}

Prime role of anaesthesiologist is to secure and maintain a patent airway. Rapid and safe endotracheal intubation is of paramount importance in general Anaesthesia. The introduction of neuromuscular blocking agents was an important development in anaesthesia practice in 1942, when Griffith and Johnson suggested that d-tubocurarine is a safe drug to use during surgery to provide skeletal muscle relaxation ${ }^{[1]}$. Muscle relaxation is used to serve two purposes: one to facilitate endotracheal intubation and other to provide surgical relaxation. While selecting neuromuscular agent for tracheal intubation or skeletal muscle relaxation, main aim of an anaesthesiologist is to select an agent with longer clinical duration of action, better hemodynamic stability and good spontaneous reversal.

Suxamethonium, a depolarizing muscle relaxant is most commonly used and considered "The Gold Standard" for tracheal intubation. The popularity of suxamethonium is questioned due to its many side effects from a mild patient discomfort (due to postoperative myalgia) up to potentially life-threatening events such as arrhythmias and malignant hyperthermia.

With the advent of newer, non-depolarizing muscle relaxants, anaesthesiologists have the luxury of other options where suxamethonium is contraindicated. Non-depolarizing neuromuscular blocking agents [NMBA] competitively inhibit acetylcholine, differ in the onset \& duration of action, metabolic route, potency, adverse effects and cost. An anaesthesiologist is able to choose NMBAs according to these similarities and differences ${ }^{[2-4]}$ Atracurium and Cisatracurium are comparatively newer nondepolarizing NMBs, intermediate acting, benzylisoquinolone compounds. It has been reported earlier that atracurium $2 \times$ ED95 dose has a faster onset of action as compared to cisatracurium 4×ED95 dose. In our study, we compared Atracurium with Cisatracurium regarding intubating conditions, onset of action \& duration of muscle relaxation with the help of Train-of-four (TOF). Train-of-four used to assess the degree of neuromuscular block by non depolarising neuromuscular blocking agents. 


\section{Aims \& objectives}

To compare intubating conditions in 2 groups.

Objectives: 1 . To compare onset of action

2. To compare duration of action

\section{Material and methods}

After Institutional ethics committee clearance, 60 patients, scheduled for various elective surgical procedures under general endotracheal anesthesia, belonging to ASA class I and II with Malampatti I and II were included in the study between 18-65 years.

\section{Inclusion criteria}

a. Patients of either sex, aged between 18-65 years.

b. Patients belonging to American Society of Anesthesiologists Grade I \& II.

c. Surgeries requiring GA with endotracheal intubation

\section{Exclusion criteria}

a. Patient refusal for the procedure.

b. Anticipated difficult intubation.

c. Neuromuscular disease

d. patient with known allergies to any drugs

\section{Methodology}

The study designed as randomized controlled double blinded clinical trial including 60 patients to compare between atracurium and cisatracurium regarding onset, duration of action, condition of intubation. Patients were randomly assigned to either groups, group A $(n=30)$ received $2 \times E D 95$ dose $(0.5 \mathrm{mg} / \mathrm{kg})$ of Atracurium, group C $(\mathrm{n}=30)$ received $4 \times \mathrm{ED} 95$ dose $(0.2 \mathrm{mg} / \mathrm{kg})$ of Cisatracurium. Detailed history \& pre-anaesthesia check up was done. Written informed consent was taken. All standard monitoring devices were attached. Patients were premedicated with Inj. Glycopyrrolate $0.004 \mathrm{mg} / \mathrm{kg}$ iv, Inj. Ondansetron $0.08 \mathrm{mg} / \mathrm{kg}$ iv, inj. Midazolam $0.03 \mathrm{mg} / \mathrm{kg}$ iv, Inj Fentanyl $2 \mathrm{mcg} / \mathrm{kg}$ iv. Patients pre-oxygenated with $100 \%$ oxygen by facemask for 3 minutes. Patients were induced with i.v propofol $2 \mathrm{mg} / \mathrm{kg}$ dose. Check ventilation was done in each patient. Anaesthesia maintained with mixture of $50 \% \mathrm{~N} 2 \mathrm{O}$ in $\mathrm{O} 2$ and isoflurane $(0.5 \%-1.5 \%$ vol\%) and assisted ventilation. Muscle relaxant in predecided doses given. Both groups were assessed for the onset of action, intubating conditions \& duration of action with the help of Train-Of-Four monitor (TOF). Neuromuscular block was continuously measured by acceleromyography (TOF every $15 \mathrm{~s}$ ). Time to maximum depression of twitch height was considered as onset of action. Time taken for spontaneous recovery to TOF score 2 was considered as duration of action. At TOF score 0 , endotracheal intubation was done.

Intubating condition were assessed according to the grading scale described in the table $1 .{ }^{[5]}$

Table 1: Intubating condition were assessed according to the grading scale described

\begin{tabular}{|c|c|c|c|}
\hline Laryngoscopy & Score 3 & Score 2 & Score 1 \\
\hline Jaw relaxation & Relaxed & Acceptable relaxation & Poor relaxation \\
\hline - Resistance to blade & None & Slight resistance & Active resistance \\
\hline \multicolumn{4}{|c|}{ Vocal cords } \\
\hline - Position & Abducted & Intermediate & Closed \\
\hline - Movement & None & Moving & Closing \\
\hline \multicolumn{4}{|c|}{ Intubation response } \\
\hline - Limb movement & None & Slight & Vigourous \\
\hline - Coughing & None & Diaphragmatic & Severe coughing or bucking \\
\hline
\end{tabular}

Excellent intubating conditions: all 3 factors rated with score of 3 .

Good intubating conditions: all 3 factors rated either with score 3 or 2.

Poor intubating conditions: presence of 1 factor rated with a score of 1 .

Excellent and good intubation conditions were considered clinically acceptable,

Whereas poor intubation conditions were considered clinically not acceptable.

\section{Statistical analysis}

Data was compiled in master chart using an excel sheet. The sample size calculated using Power Analysis software.
Categorical variables were expressed as actual numbers and percentages. Continuous variables were expressed as mean and standard deviations. Between groups, analysis was done using unpaired T-test. $\mathrm{P}$ value less than 0.005 was considered statistically significant.

\section{Results}

Table 2: Gender \& ASA distribution

\begin{tabular}{|c|c|c|c|}
\hline Gender & I & II & Total \\
\hline Female & 14 & 19 & 33 \\
\hline Male & 12 & 15 & 27 \\
\hline Total & 26 & 34 & 60 \\
\hline
\end{tabular}

Table 3: Intubating conditions after administration of Atracurium \& Cisatracurium

\begin{tabular}{|c|c|c|}
\hline Condition of Intubation & Group A $(\mathbf{n = 3 0})$ & Group C $(\mathbf{n = 3 0})$ \\
\hline Excellent & 12 & 15 \\
\hline Good & 18 & 15 \\
\hline Poor & 0 & 0 \\
\hline Not possible & 0 & 0 \\
\hline
\end{tabular}

As it is seen in table 3 , group A who received $2 \times$ ED95 $(0.5 \mathrm{mg} / \mathrm{kg})$ of Atracurium $12(40 \%)$ patients out of 30 had excellent intubating conditions, $18(60 \%)$ patients had good intubating conditions. In group $\mathrm{C}$, who received $4 \times \mathrm{ED} 95$ dose $(0.2 \mathrm{mg} / \mathrm{kg})$ of Cisatracurium $15(50 \%)$ patients out of 30 had excellent intubating conditions, $15(50 \%)$ patients 
had good intubating conditions. There was not any case of not possible intubation among the studied groups. Difference in mean Intubating conditions score was not statistically significant.

Table 4: Onset \& duration of neuromuscular blockade after administration of Atracurium \& Cisatracurium

\begin{tabular}{|c|c|c|}
\hline Group & $\begin{array}{c}\text { Mean onset time } \\
\text { (minutes) }\end{array}$ & $\begin{array}{c}\text { Mean duration of action } \\
\text { (minutes) }\end{array}$ \\
\hline Group A & $3.78 \pm 0.49$ & $38.93 \pm 4.93$ \\
\hline Group C & $6.07 \pm 1.26$ & $59.43 \pm 9.09$ \\
\hline
\end{tabular}

Mean onset time for group A was 3.7 minutes which was faster as compared to group C 6.04 minutes \& difference was highly significant $(\mathrm{p}<0.005)$. Mean duration of action for group $\mathrm{C}$ was 59.43 minutes which was significantly more compared to group A 38.93 minutes $(\mathrm{p}<0.005)$.

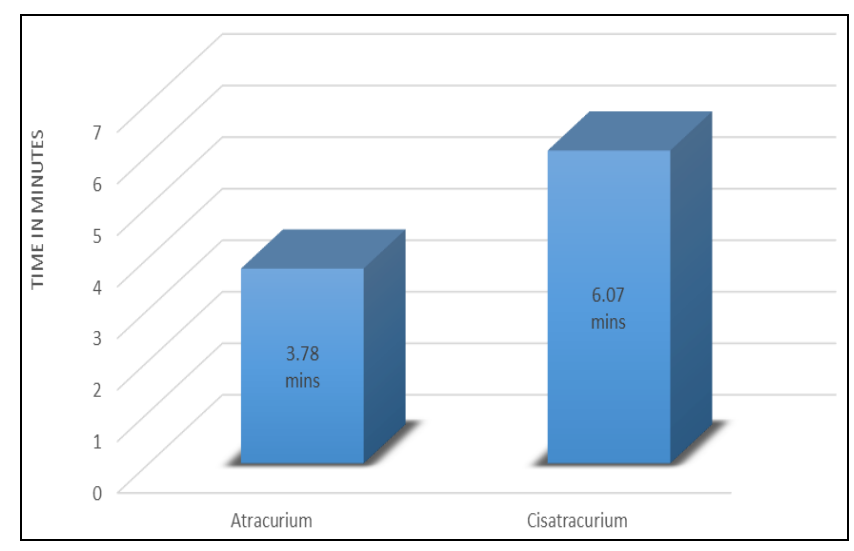

Fig 1: Mean Onset of Action of Neuromuscular Blockade

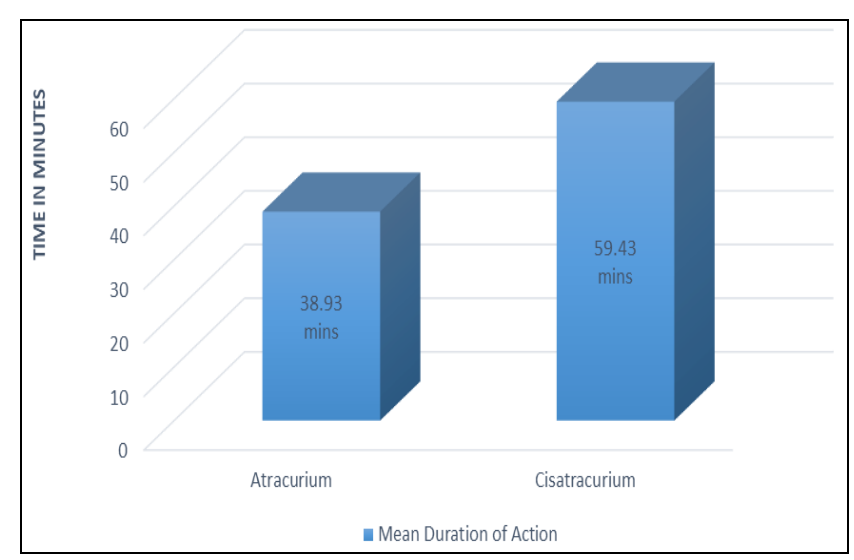

Fig 2. Mean Duration of Action of Neuromuscular Blockade

\section{Discussion}

Neuromuscular blocking drugs are extensively used by anaesthesiologists in the operating room and in the intensive care units. In selecting a neuromuscular blocking agent to facilitate tracheal intubation or skeletal muscle relaxation an anaesthetist strives to achieve three competing goals: (1) Adequate muscle relaxation, (2) Haemodynamic stability, and (3) Devoid of any side effects.

Two non-depolarising muscle relaxants of intermediate duration of action, Atracurium and Cisatracurium besylate having significant advantage over other non-depolarising muscle relaxants due to their non-organ dependent metabolism were compared in this study. Both the groups were comparable regarding patient's age and gender.
The speed of onset is inversely proportional to the potency of non-depolarizing neuromuscular blocking agents. It has been reported earlier that Atracurium 2xED95 dose has a faster onset of action as compared to Cisatracurium 4×ED95 dose. Presumably, Cisatracurium has greater potency than Atracurium resulting in fewer molecules being administered even with the higher doses. So Cisatracurium with higher doses has faster onset of action as compared to Atracurium [6].

In a study done by El-Kasaby et al, in which they studied Atracurium 2xED95 dose with Cisatracurium (2xED95, $4 \times$ ED95 \& 6×ED95). Regarding the condition of intubation, their findings were, $2 \times E D 95$ dose of Atracurium, and $2 \times$ ED95 and $4 \times$ ED95 doses of Cisatracurium were similar while $6 \times$ ED95 dose of Cisatracurium was significantly better than Atracurium. They also studied the time onset of neuromuscular blockade and duration of action. With respect to these parameters time onset was found to be significantly lower with $2 \times$ ED95 dose of Atracurium than with the same dose of Cisatracurium. At the same time, higher dose of Cisatracurium (4×ED95) showed onset time that was significantly lower than with Atracurium and with lower dose of Cisatracurium $\left(2 \times\right.$ ED95) ${ }^{[7] .}$

Bakhshi et al studied Cisatracurium Besylate (4×ED95) versus Atracurium Besylate $(2 \times E D 95)$ in Adult Surgical Patients. Mean Duration of action in Cisatracurium group was 61.50 minute which was significantly more as compared to 38.57 minute in Atracurium group. In our study, duration of action was $38.9 \pm 4.9 \min \& 59.43 \pm 9.09$ min for Atracurium $0.5 \mathrm{mg} / \mathrm{kg}$ and Cisatracurium $0.2 \mathrm{mg} / \mathrm{kg}$ dose. Regarding the mean duration of action ( $\mathrm{min}$ ) our result was similar to the results of Bakshi et al. ${ }^{[8]}$

Shang Guan in his study, reported that with the increasing doses of NMBA, the duration of clinical action was prolonged and risk of postoperative residual block increases. So, proper selection of dose can ensure the desired effect without excessive over dosage ${ }^{[9]}$.

Movafegh, S. Amini, H. Sharifnia, H. Torkamandi, A. Hayatshahi, M. Javadi Compared cost analysis and safety of Cisatracurium and Atracurium in patients undergoing general anesthesia. They found safety profile of both the drugs to be similar, which was seen in our study also. In their study, they found Atracurium had cost benefit over Cisatracurium. In our study, we did not compared cost analysis of both drugs ${ }^{[10]}$.

\section{Conclusion}

We conclude that both the drugs provide comparable intubating conditions. Atracurium $2 \times E D 95$ dose has faster onset \& shorter duration of muscle relaxation than Cisatracurium $4 \times$ ED95 dose.

\section{References}

1. Bodman RI, Gillies D. Harold Griffith: The Evolution of Modern Anaesthesia. Toronto, Canada: Hannah Institute \& Dundurn Press, 1992.

2. Movafeghetal. "Cost analysis and safety comparison of Cisatracurium and Atracurium in patients undergoing general anesthesia" (European Review for Medical and Pharmacological Sciences. 2013; 17:447-50.

3. Moore EW, Hunter JM. The new neuromuscular blocking agents: do they offer any advantages $\mathrm{Br}$. Janaesth. 2001; 87:912-25.

4. Mertes PM, Laxenaire MC. Adverse reactions to 
neuromuscular blocking agents. Curr Allergy Asthma Rep. 2004; 4:7-16

5. Viby-Mogensen J, Englbaek J, Eriksson LI et al. Good clinical research practice (GCRP) in pharmacodynamic studies of neuromuscular blocking agents. Acta Anaesthesiol Scand. 1996; 40:59-74.

6. Miller's Anaesthesia 7th ed, Churchill Livingston 2010 g.868, 869, 876, table 29-6, page 872, table 29-4, 29-7, page 874 , page 881 table $29-4,890$.

7. El-Kasaby et al. Cisatracurium in different doses; Saudi Journal of Anaesthesia. 2010; 4(3).

8. Dr. Rochana G Bakhshi et al JMSCR Page 14613 ... Cisatracurium Besylate versus Atracurium Besylate in Adult Surgical. 2016; 4(12).

9. Shang Guan, Wang Ning, Lian, Qing Quan, Li Jun, Gao. Fang Clinical pharmacology of cisatracurium during nitrous oxide-propofol anesthesia in children. Journal of Clinical Anesthesia. 2008; 20(6):411-4.

10. Movafegh A, Amini S, Sharifnia H, Torkamandi H, Hayatshahi A, Javadi M. European Review for Medical and Pharmacological Sciences. 2013; 17:447-450. 